\title{
Parameters influencing transient and stable transformation of barley (Hordeum vulgare L.) protoplasts
}

\author{
J. Zhang, V.K. Tiwari, T.J. Golds, N.W. Blackhall, E.C. Cocking, B.J. Mulligan, J.B. Power \& \\ M.R. Davey* \\ Plant Genetic Manipulation Group, Department of Life Science, University of Nottingham, University Park, \\ Nottingham NG7 2RD, UK (*requests for offprints)
}

Plant Cell, Tissue and Organ Culture 41: 125-138, 1995

Due to an error in the final printing stage, Figure 4 of this publication has been printed upside down in relation to its labels. The correct figure is presented below.

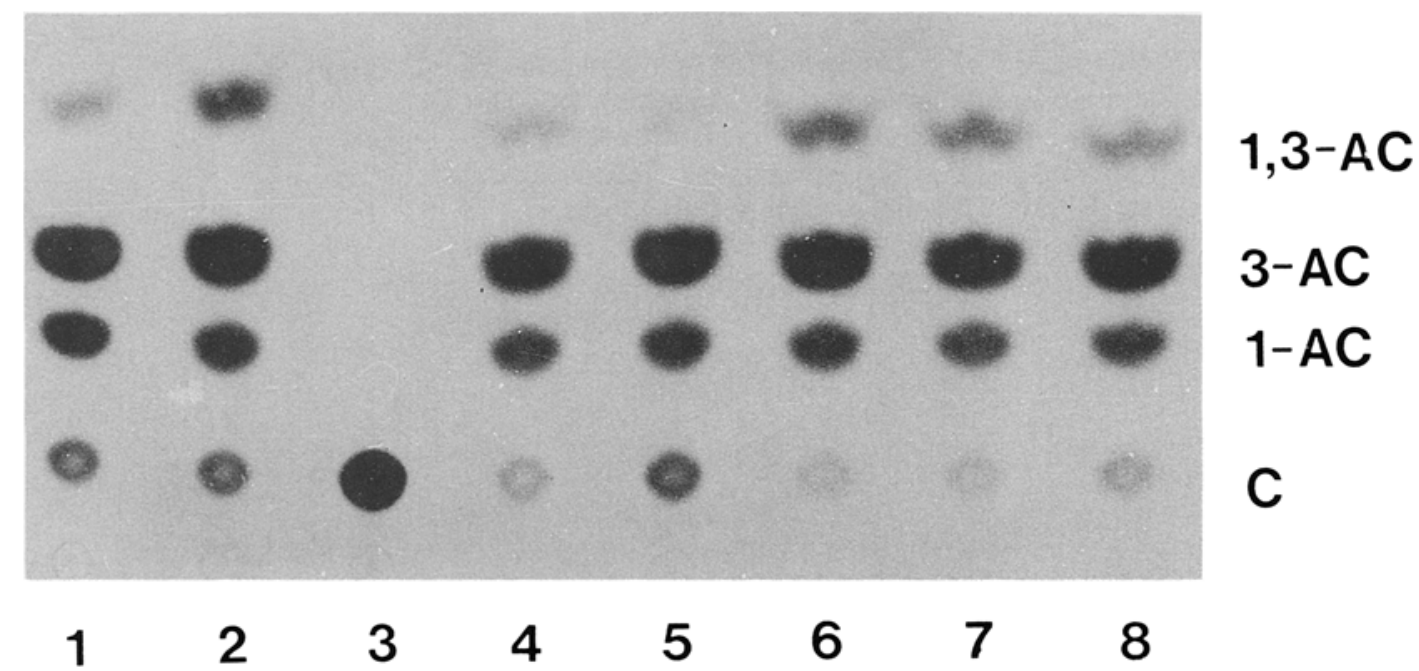

Fig. 4. Autoradiograph prepared from a chromatograph of CAT reaction products. The Fig. illustrates the effect of pCaMVI $\mathrm{CN}_{1}$ concentration on CAT activity in protoplasts isolated from an 8-month old cell suspension. Extracts were prepared for CAT assay $36 \mathrm{~h}$ after uptake of $\mathrm{pCaMVI}_{1} \mathrm{CN}(20 \%$ (w/v) PEG). The autoradiograph was exposed to X-ray film for $72 \mathrm{~h}$. (C: chloramphenicol; 1-AC: 1 , mono-acetyl chloramphenicol; 3-AC: 3, mono-acetyl chloramphenicol; 1,3-AC: 1,3, di-acetyl chloramphenicol). Percentage conversion of chloramphenicol to acetylated chloramphenicol is given for each treatment. Lanes 1 and 2: Positive control [bacterial standard; 1 and 5 units respectively of purified CAT (Sigma); 94\%]; Lane 3: Negative control (protoplasts mixed with plasmid without PEG treatment: 0\%); Lane 4: Protoplasts mixed with $50 \mu \mathrm{g} \mathrm{sample}^{-1}$ of pDW2 prior to PEG treatment (96\%); Lane 5, 6, 7 and 8: Protoplasts mixed with 5, 25, 50 and $100 \mu \mathrm{g}$ sample ${ }^{-1}$ of $\mathrm{pCaMVI}_{1} \mathrm{CN}$ prior to $\mathrm{PEG}$ treatment $(91 \%, 98 \%, 98 \%, 96 \%$ respectively). 